\title{
Analisis Vegetasi Strata Semak Berdasarkan Cluster Lingkungan Abiotik di Sempadan Sungai Tepus Sleman, Yogyakarta sebagai Sumber Belajar Biologi SMA Kelas $\mathbf{X}$
}

\author{
Trikinasih Handayani , Yusi Yustiah \\ Progam Studi Pendidikan Biologi, Universitas Ahmad Dahlan \\ Kampus III, Jl. Prof. Dr. Soepomo, SH, Yogyakarta, 55164 Indonesia
}

\begin{abstract}
ABSTRAK
Penelitian ini bertujuan untuk mengetahui jenis-jenis strata semak yang memiliki peranan paling besar berdasarkan indeks nilai pentingnya, indeks diversitas jenis-jenis strata semak, dan hubungan antara faktor lingkungan abiotik yang terukur meliputi: kelembaban udara, suhu udara, suhu tanah, $\mathrm{pH}$ tanah, unsur $\mathrm{N}$, unsur P, unsur K, dan KPK tanah dengan pola pengelompokkan stand vegetasi strata semak di sempadan Sungai Tepus Sleman, Yogyakarta, serta untuk mengetahui apakah proses dan hasil penelitian analisis vegetasi strata semak berdasarkan cluster lingkungan abiotik di sempadan Sungai Tepus Sleman, Yogyakarta, memiliki potensi sebagai sumber belajar biologi SMA kelas X pada materi pembelajaran struktur dan fungsi ekosistem terestrial.

Pengamatan terhadap jenis-jenis strata semak menggunakan metode point centered quarter. Lokasi penelitian dilakukan di sepanjang sempadan Sungai Tepus Sleman, Yogyakarta, dengan masing-masing luas area kajian $383.333 \mathrm{~m} 2$. Setiap area kajian di buat 20 stand, dan setiap stand diletakkan garis transek utama sepanjang $300 \mathrm{~m}$, selanjutnya dibuat I0 titik sampling yang memotong transek utama yang berjarak masingmasing $30 \mathrm{~m}$. Metode analisis cluster bertujuan untuk mengetahui hubungan antara faktor lingkungan abiotik yang terukur dengan pola pengelompokkan stand vegetasi strata semak di sempadan Sungai Tepus Sleman, Yogyakarta. Penghitungan metode ini dibantu dengan program SPSS versi I6.

Hasil penelitian menunjukkan bahwa di sempadan Sungai Tepus Sleman, Yogyakarta telah ditemukan 19 jenis strata semak. Jenis-jenis strata semak yang memiliki rerata INP tertinggi yaitu Bambusa sp. 120,77\%, Musa paradisiaca L. 67,92\%, dan Manihot utillissima Pohl. 30,07\%. Indeks diversitas jenis-jenis strata semak yaitu 0,54. Berdasarkan analisis cluster dapat dikelompokkan menjadi dua cluster. Faktor lingkungan abiotik yang berkaitan dengan pola pengelompokkan stand vegetasi strata semak yaitu suhu udara, unsur nitrogen $(\mathrm{N})$, unsur hara fosfor $(\mathrm{P})$, kalium $(\mathrm{K})$, dan kapasitas pertukaran kation (KPK). Akan tetapi, faktor lingkungan abiotik yang tidak berkaitan dengan pola pengelompokkan stand yaitu kelembaban udara, suhu tanah, dan $\mathrm{pH}$ tanah. Melalui hasil pengkajian penelitian ini dapat digunakan sebagai sumber belajar biologi SMA kelas X pada materi pembelajaran struktur dan fungsi ekosistem terestrial.
\end{abstract}

Kata kunci: Analisis vegetasi, Strata semak, Sempadan sungai

\section{Pendahuluan}

Sungai merupakan sumber daya air yang memiliki manfaat untuk kehidupan manusia dan alam. Namun, keberadaan air sungai saat ini telah mengalami penurunan kualitas air. Hal ini disebabkan oleh adanya berbagai polutan yang masuk dan bercampur dengan air sungai, sehingga air tampak keruh dan kotor. Pencemaran air sungai dapat dicegah dengan memanfaatkan tumbuhan yang hidup di sekitar sempadan sungai. Sempadan sungai merupakan area sepanjang kiri kanan sungai yang berfungsi sebagai batas perlindungan sungai. Tumbuhan yang hidup di sempadan sungai terdiri dari tumbuhan paku, herba, semak, dan pohon. Akar-akar tumbuhan tersebut mampu menyaring berbagai polutan sehingga dapat meminimalkan pencemaran dan mempertahankan kualitas air.

Salah satu bagian dari daerah aliran sungai adalah sempadan sungai. Sempadan sungai merupakan kawasan sepanjang kiri dan kanan sungai sebagai batas perlindungan sungai yang bermanfaat untuk mempertahankan kelestarian fungsi sungai. Penetapan sempadan sungai yang tidak bertangggul dan diluar kawasan perkotaan pada sungai kecil ditetapkan 
50 meter dihitung dari tepi sungai dari waktu yang ditetapkan.

Daerah Aliran Sungai Tepus terletak di Kabupaten Sleman. Sungai ini merupakan bagian dari anak Sungai Opak yang memiliki panjang alur $23 \mathrm{~km}$ (Pejabat Pembuat Komitmen Pengendalian Lahar Gunung Merapi, 2013). Daerah ujung DAS Tepus terletak di Desa Wukirsari, Kecamatan Cangkringan, dan daerah akhirnya merupakan tempat pertemuan antara Sungai Tepus dan Sungai Opak yang terletak di Desa Tegaltirto, Kecamatan Berbah.

Vegetasi yang tumbuh di sempadan Sungai Tepus Sleman, Yogyakarta terdiri dari vegetasi strata pohon, strata semak, dan strata herba. Keberadaan vegetasi yang tumbuh di wilayah itu sangat mempengaruhi faktor lingkungan di sekitarnya. Vegetasi merupakan pencerminan interaksi berbagai faktor lingkungan dengan makhluk hidup (Heddy, 20I2: II8). Vegetasi ini mencerminkan keadaan iklim, tanah, tersedianya air, dan hara bermacam-macam pengaruh faktor bioitk (hayati) termasuk manusia. Selain itu, vegetasi juga berperan dalam proses transpirasi (penguapan air). Transpirasi vegetasi yang tinggi dapat menambah kemampuan tanah untuk menyerap dan menahan air hujan, sehingga dapat mencegah terjadinya erosi. Menurut Djufri (2003: 32) menyatakan bahwa tumbuhan dapat digunakan sebagai indikator suatu lingkungan dan alat ilmiah untuk menganalisis lingkungan.

Salah satu vegetasi yang tumbuh di sempadan Sungai Tepus Sleman, Yogyakarta yang dapat menarik perhatian adalah vegetasi strata semak. Strata semak ini merupakan tumbuhan berkayu yang tidak memiliki batang tunggal tetapi bercabang-cabang dekat permukaan tanah, dan memiliki ketinggian kurang dari 8 $\mathrm{m}$. Banyaknya vegetasi strata semak ini kurang mendapat perhatian dari masyarakat padahal dilihat dari segi manfaat kandungan kimia dalam tiap organnya yang dapat digunakan untuk mengobati berbagai macam penyakit.

Dari segi kependidikan, pembelajaran biologi merupakan pembelajaran yang menekankan pada pemberian pengalaman secara langsung. Sehingga diperlukan upaya untuk membantu siswa dalam mengembangkan sejumlah keterampilan proses agar mereka mampu memahami materi yang disajikan. Salah satunya adalah dengan memanfaatkan lingkungan sebagai sumber belajar. Menurut Kentish (Hendriani, 2005: 3) menyatakan bahwa lingkungan sebagai sumber belajar dapat menciptakan dan meningkatkan kesadaran siswa terhadap lingkungan. Makin tinggi kesadaran seseorang terhadap lingkungan makin terwujud dalam tingkah laku. Lingkungan telah menyediakan berbagai macam informasi yang kongkrit mengenai kehidupan sehari-hari untuk dijadikan bahan pelajaran. Salah satu lingkungan yang dapat dijadikan sebagai sumber belajar adalah sempadan Sungai Tepus Sleman, Yogyakarta.
Hasil pengamatan di sempadan Sungai Tepus Sleman, Yogyakarta memiliki fenomena alam yang berpotensi sebagai sumber belajar. Fenomena alam yang dipilih sebagai sumber belajar adalah jenis-jenis strata semak yang menarik dari segi keunikan, keindahan, dan kegunaannya serta faktor lingkungan abiotik yang mempengaruhi pertumbuhannya. Salah satu contoh jenis strata semak yang mudah dikenal dan ditemukan di sempadan sungai ini yaitu Manihot utillissima Pohl. atau sebutan nama lainnya adalah ubi singkong. Keunikan yang menonjol dari jenis ini adalah bentuk daunnya berbagi tiga sampai sembilan. Ubi singkong merupakan salah satu jenis tumbuhan yang berbentuk perdu dan dapat tumbuh di daerah terbuka. Masyarakat memanfaatkan ubi singkong ini sebagai makanan pokok. Selain itu, manfaat lain dari ubi singkong ini adalah daun, batang, dan umbinya yang berkhasiat untuk mengobati luka bernanah, demam, dan penyakit beriberi. Sehingga fenomena alam di sempadan sungai Tepus Sleman, Yogyakarta mempunyai manfaat untuk dijadikan sebagai sumber belajar biologi. Pemanfaatan fenomena alam di sempadan sungai sebagai sumber belajar diperlukan penelitian terlebih dahulu sebelum dijadikan sebagai sumber belajar. Setelah itu, hasil penelitian di sempadan Sungai Tepus Sleman, Yogyakarta ini dapat dijadikan sebagai sumber belajar biologi SMA kelas X pada materi pembelajaran struktur dan fungsi ekosistem terestrial.

\section{Metode Penelitian}

Jenis penelitian ini adalah penelitian eksploratif. Metode penelitian yang digunakan adalah point centered quarter (PCQ). populasi dan sample yang digunakan adalah penelitian ini adalah vegetasi strata semak di sempadan Sungai Tepus Sleman, Yogyakarta. Metode PCQ merupakan salah satu jenis dari metode kuadran yang mudah dan lebih cepat digunakan untuk mengetahui komposisi, dominansi semak dan menaksir volumenya. Metode ini dapat digunakan untuk populasi semak yang pengelompokkannya tinggi (mengelompok) atau menempati ruang secara seragam (Soegianto, 1994: 28).

\section{Hasil dan Pembahasan}

Indeks nilai penting (INP) merupakan suatu indeks yang dihitung berdasarkan jumlah seluruh densitas relatif (KR), frekuensi relatif (FR), dan dominansi relatif (DR). INP menggambarkan pentingnya peranan suatu jenis vegetasi dalam suatu ekosistemnya. Berikut ini hasil rerata indeks nilai penting di sempadan Sungai Tepus Sleman, Yogyakarta.

Indeks nilai penting jenis-jenis strata semak pada area kajian A (Daerah Ujung) tertera pada Tabel I. menunjukkan bahwa pada area kajian A ditemukan 8 jenis strata semak, diantaranya: Bambusa sp., Musa paradisiaca L., Manihot utillissima Pohl., Eupatorium 
odoratum L.f., Eupatorium triplinerve Vahl., Carica papaya L., Mimosa invisa Mart., dan Salacca edulis Reinw.

Tabel I. Rerata INP Jenis-jenis Strata Semak pada Area Kajian A

\begin{tabular}{|c|c|c|}
\hline Nama Spesies & $\begin{array}{c}\text { Rerata } \\
\text { INP } \\
(\%)\end{array}$ & Rerata INP (\%) \\
\hline Bambusasp. & II 3,75 & $\begin{array}{l}\mathrm{I}, 2,3,4,5,6,7,8,9, \mathrm{I} 0, \mathrm{II}, \mathrm{I} 2, \mathrm{I} 3, \mathrm{I} 4, \mathrm{I} 5, \\
\mathrm{I} 6, \mathrm{I}, \mathrm{I} 8, \mathrm{I} 9,20\end{array}$ \\
\hline Musa paradisiaca L. & I02,47 & $\begin{array}{l}\mathrm{I}, 2,3,4,5,6,7,8,9, \mathrm{I} 0, \mathrm{I} \mathrm{I}, \mathrm{I} 2, \mathrm{I} 3, \mathrm{I} 4, \mathrm{I} 5, \\
\mathrm{I} 6, \mathrm{I} 7, \mathrm{I} 8, \mathrm{I} 9,20\end{array}$ \\
\hline $\begin{array}{l}\text { Manihot utillissima } \\
\text { Pohl. }\end{array}$ & 36,69 & $\begin{array}{l}\mathrm{I}, 3,4,5,6,7,8,9, \mathrm{I} 0, \mathrm{I} \mathrm{I}, \mathrm{I} 2, \mathrm{I} 3, \mathrm{I} 4, \mathrm{I} 5, \\
\mathrm{I} 6, \mathrm{I} 7, \mathrm{I} 8,20\end{array}$ \\
\hline $\begin{array}{l}\text { Eupatorium } \\
\text { odoratum L.f. }\end{array}$ & $\mathrm{I} 7,72$ & $\mathrm{I}, 2,3,4,5, \mathrm{I} I, \mathrm{I} 3, \mathrm{I} 4, \mathrm{I} 6, \mathrm{I} 7, \mathrm{I} 8, \mathrm{I} 9,20$ \\
\hline $\begin{array}{l}\text { Eupatorium } \\
\text { triplinetve Vahl. }\end{array}$ & $\mathrm{I} 4,09$ & $\mathrm{I}, 2,3,4,5,6,9, \mathrm{I} \mathrm{I}, \mathrm{I} 4, \mathrm{I} 8,20$ \\
\hline Carica papaya L. & $\mathrm{I3}, \mathrm{I} 9$ & $2,4,6,8,9, \mathrm{I0}, \mathrm{I} 8$ \\
\hline Mimosa invisa Mart. & $\mathrm{I}, 77$ & $\mathrm{I}, 2$ \\
\hline $\begin{array}{l}\text { Salacca edulis } \\
\text { Reinw. }\end{array}$ & 0,33 & $\mathrm{I}$ \\
\hline Jumlah & 300 & \\
\hline
\end{tabular}

Di area kajian ini diperoleh hasil bahwa jenis-jenis strata semak yang memiliki rerata INP tertinggi, yaitu Bambusa sp. I 13,75\%, Musa paradisiaca L. I02,47\%, dan Manihot utillissima Pohl. 36,69\%. Sebaliknya, jenis-jenis strata semak yang memiliki rerata INP terendah, yaitu Carica papaya L. 13,19\%, Mimosa invisa Mart. I,77\%, dan Salacca edulis Reinw.

Area kajian B ditemukan I5 jenis strata semak, diantaranya: Bambusa sp., Musa paradisiaca L., Manihot utillissima Pohl., Eupatorium odoratum L.f., Carica papaya L., Salacca edulis Reinw., Acalypha indica L., Sida ocuta Burm.f., Urena lobata L., Mimosa invisa Mart., Capsicum frutescens L., Clerodendron squamatum Vahl., Cassia laevigata Wild., Vinca rosea L., Costus megalobrachtea K. Schum terlihat dalam Tabel 2.

Tabel 2. Rerata Indeks Nilai Penting Jenis-jenis Strata Semak pada Area Kajian B

\begin{tabular}{|c|c|c|}
\hline Nama Spesies & $\begin{array}{l}\text { Rata-rata } \\
\text { INP (\%) }\end{array}$ & Tempat Stand \\
\hline Bambusa sp. & II 9,4 I & $\begin{array}{l}2 \mathrm{I}, 22,24,25,26,27,28,29,30,3 \mathrm{I}, \\
32,33,36,37,38,60\end{array}$ \\
\hline Musa paradisiaca L. & 65,62 & $\begin{array}{l}2 \mathrm{I}, 23,24,26,27,28,3 \mathrm{I}, 33,36,37, \\
38,39,40\end{array}$ \\
\hline $\begin{array}{l}\text { Manihot utillissima } \\
\text { Pohl. }\end{array}$ & 34,87 & $\begin{array}{l}22,23,25,27,29,3 \mathrm{I}, 33,34,36,37, \\
38,39,40\end{array}$ \\
\hline Carica papaya L. & 25,58 & $23,24,25,27,28,29,30,35,36,37$ \\
\hline Urena lobata L. & I6, I0 & $26,29,34,35,36,39,40$ \\
\hline Acalypha indica Vahl. & 10,66 & $2 \mathrm{I}, 22,23,24,28,29,35,37,40$ \\
\hline Sida ocuta Burm.f & 9,93 & $2 \mathrm{I}, 23,24,25,29,37,39$ \\
\hline $\begin{array}{l}\text { Eupatorium odoratum } \\
\text { L.f. }\end{array}$ & 4,77 & $24,33,35$ \\
\hline Capsicum frutescens $\mathrm{L}$. & 3,76 & $23,34,38$ \\
\hline Salacca edulis Reinw. & 2,24 & $22,27,38$ \\
\hline Mimosa invisa Mart. & $\mathrm{I}, 94$ & $25,35,40$ \\
\hline Cassia laevigata Wild. & $\mathrm{I}, 69$ & 30,33 \\
\hline Vinca rosea L. & $\mathrm{I}, 20$ & 22,30 \\
\hline $\begin{array}{l}\text { Clerodendron } \\
\text { squamatum Vahl. }\end{array}$ & $\mathrm{I}, \mathrm{I} 2$ & 30,32 \\
\hline $\begin{array}{l}\text { Costus megalobrachtea } \\
\text { K. Schum. }\end{array}$ & $\mathrm{I}, \mathrm{I} 2$ & 36 \\
\hline Jumlah & 300 & \\
\hline
\end{tabular}

Di area kajian ini, jenis-jenis strata semak yang memiliki rerata INP tertinggi, terdiri dari Bambusa sp. I 19,4I\%, Musa paradisiaca L. 65,62\%, dan Manihot utillissima Pohl.. 34,87\%. Sebaliknya, jenis-jenis strata semak yang memiliki rerata INP terendah, yaitu Vinca rosea L. I,20\%, Clerodendron squamatum Vahl. I,I2\%, dan Costus megalobrachtea K. Schum. I,I2\%.

Area kajian C pada Tabel 3. ditemukan 12 jenis strata semak, diantaranya: Bambusa sp., Musa paradisiaca L., Manihot utillissima Pohl., Eupatorium odoratum L.f., Carica papaya L., Acalypha indica L., Mirabilis jalapa L., Leucas lavandulifolia Smith., Costus megalobrachtea K. Schum., , Sida ocuta Burm.f., Urena lobata L., dan Nothopanax scutellarium Merr..

Tabel 3. Rerata Indeks Nilai Penting Jenis-jenis Strata Semak pada Area Kajian C

\begin{tabular}{|c|c|c|}
\hline Nama Spesies & $\begin{array}{l}\text { Rata-rata } \\
\text { INP }(\%)\end{array}$ & Tempat Stand \\
\hline Bambusa sp. & I29,I5 & $\begin{array}{l}4 \mathrm{I}, 42,43,44,46,47,48,49,50, \\
5 \mathrm{I}, 52,53,54,55,56,58,59,60\end{array}$ \\
\hline Musa paradisiaca L. & 35,67 & $4 \mathrm{I}, 42,46,47,48,50,52,56$ \\
\hline Carica papaya $L$. & $22, \mathrm{I} 4$ & $44,45,48,49,56,60$ \\
\hline Sida ocuta Burm.f. & 19,37 & $44,46,47,48,55,56,57,59$ \\
\hline Manihot utillissima Pohl. & 18,65 & $43,45,46,47,48,53,58$ \\
\hline Urena lobata L. & 17,50 & $4 \mathrm{I}, 43,45,46,52,57$ \\
\hline $\begin{array}{l}\text { Eupatorium odoratum } \\
\text { L.f. }\end{array}$ & $\mathrm{I} 5,79$ & $44,48,53,54,56,59,60$ \\
\hline Acalypha indica L. & $\mathrm{II}, 95$ & $4 \mathrm{I}, 42,47,54,55,59$ \\
\hline $\begin{array}{l}\text { Costus megalobrachtea } \\
\text { K. Schum. }\end{array}$ & 9,00 & $4 \mathrm{I}, 46,48,50,5 \mathrm{I}, 56,60$ \\
\hline $\begin{array}{l}\text { Leucas lavandulifolia } \\
\text { Smith. }\end{array}$ & 8,12 & $49,5 \mathrm{I}, 53,57,58$ \\
\hline Mitabilis jalapa L. & 7,02 & $42,47,48,49,52,60$ \\
\hline $\begin{array}{l}\text { Nothopanax scutellarium } \\
\text { Merr. }\end{array}$ & 5,64 & $4 \mathrm{I}, 42,48,49,59$ \\
\hline Bambusa sp. & I29,I5 & $\begin{array}{l}4 \mathrm{I}, 42,43,44,46,47,48,49,50, \\
5 \mathrm{I}, 52,53,54,55,56,58,59,60\end{array}$ \\
\hline Jumlah & 300 & \\
\hline
\end{tabular}

Jenis-jenis strata semak yang memiliki rerata INP tertinggi di area kajian C, terdiri dari Bambusa sp 129,I5\%, Musa paradisiaca L. 35,67\%., dan Carica papaya L. 22,I4\%. Sebaliknya, jenis-jenis strata semak yang memiliki rerata INP terendah, yaitu Leucas lavandulifolia Smith. 8,I2\%, Mirabilis jalapa L. 7,02\%, dan Nothopanax scutellarium Merr.

Jumlah Indeks Nilai Penting (INP) padaa Tabel 4. di sempadan Sungai Tepus dikategorikan tinggi, yaitu sebesar 300\% karena nilai pentingnya setiap jenis dalam suatu komunitas berkisar antara 0-300 (Barbour, I942: 194). Artinya, jenis-jenis strata semak yang tumbuh di daerah tersebut mampu mempengaruhi tingkat kestabilan ekosistem sempadan Sungai Tepus. Adapun jenis-jenis strata semak yang memiliki rerata INP tertinggi, terdiri dari Bambusa sp. I20,77\%, Musa paradisiaca L. 67,92\%, dan Manihot utillissima Pohl. 30,07\%. Jenis-jenis strata semak yang memiliki rerata INP terendah, yaitu Cassia laevigata Wild. 0,56\%, Vinca rosea L. 0,40\%, dan Clerodendron squamatum Vahl. 0,37\%. 
Tabel 4. Rerata INP Jenis-jenis Strata Semak Seluruh Area Kajian di Sempadan Sungai Tepus Sleman, Yogyakarta

\begin{tabular}{lc}
\hline \multicolumn{1}{c}{ Nama Spesies } & Rata-rata INP (\%) \\
\hline Bambusa sp. & $\mathrm{I} 20,77$ \\
\hline Musa paradisiaca L. & 67,92 \\
\hline Manihot utillissima Pohl. & 30,07 \\
\hline Carica papaya L. & 20,30 \\
\hline Eupatorium odoratum L.f. & $\mathrm{I} 2,76$ \\
\hline Urena lobata L. & $\mathrm{I}, 20$ \\
\hline Sida ocuta Burm.f. & 9,77 \\
\hline Acalypha indica L. & 7,54 \\
\hline Eupatorium triplinerve Vahl. & 4,70 \\
\hline Costus megalobrachtea K. Schum. & 3,37 \\
\hline Leucas lavandulifolia Smith. & $2,7 \mathrm{I}$ \\
\hline Mirabilis jalapa L. & 2,34 \\
\hline Nothopanax scutellarium Merr. & $\mathrm{I}, 88$ \\
\hline Capsicum frutescens L. & $\mathrm{I}, 25$ \\
\hline Mimosa invisa Mart. & $\mathrm{I}, 24$ \\
\hline Salacca edulis Reinw. & 0,85 \\
\hline Cassia laevigata Wild. & 0,56 \\
\hline Vinca rosea L. & 0,40 \\
\hline Cletodendron squamatum Vahl. & 0,37 \\
\hline Bambusa sp. & $\mathrm{I} 20,77$ \\
\hline Jumlah & 300 \\
\hline
\end{tabular}

Berdasarkan luas area atau daerah distribusi, tumbuhan dibedakan menjadi tumbuhan kosmopolit dan tumbuhan endemik. Tumbuhan kosmopolit merupakan tumbuhan yang daerah distribusinya luas atau terdapat dimana-mana dan area penyebarannya luas. Sebaliknya, tumbuhan endemik merupakan tumbuhan yang penyebarannya terbatas di wilayah yang tidak terlalu luas, yang disebabkan oleh kondisi lingkungan setempat (Fitriyani, dkk., 2013).

Area kajian A memiliki indeks diversitas 0,56, area kajian B memiliki indeks diversitas 0,52, dan area kajian C memiliki indeks diversitas 0,52. Menurut Fachrul (2012: 53), menyatakan bahwa nilai $H^{\prime}<\mathrm{I}$, menunjukkan bahwa indeks diversitas pada suatu transek adalah sedikit atau rendah. Indeks diversitas yang rendah telah menggambarkan bahwa stabilitas ekosistem di daerah tersebut kurang baik. Hasil rerata indeks diversitas yang tertinggi pada area kajian A terletak pada stand I sebesar 0,74 , area kajian B terletak pada stand 37 sebesar 0,69 dan area kajian C terletak pada stand 48 sebesar 0,76 .

Faktor lingkungan abiotik yang terukur dalam penelitian ini, diantaranya kelembaban udara, suhu udara, suhu tanah, $\mathrm{pH}$ tanah, unsur hara nitrogen $(\mathrm{N})$, fosfor (P), kalium (K) dan kapasitas pertukaran kation (KPK). Kondisi lingkungan abiotik yang terukur seluruh area kajian di sempadan Sungai Tepus Sleman, Yogyakarta, yaitu kelembaban udara berkisar antara $53 \%-75 \%$, suhu udara antara $27^{\circ} \mathrm{C}-3 \mathrm{I}^{\circ} \mathrm{C}$, suhu tanah antara $25^{\circ} \mathrm{C}-32^{\circ} \mathrm{C}$, $\mathrm{pH}$ tanah antara $5,5-6$, unsur $\mathrm{N}$ $536,43 \mathrm{mg} / \mathrm{kg}$, unsur P 498,54 mg/kg, unsur K 769,05 $\mathrm{mg} / \mathrm{kg}$, dan KPK tanah 9,06 me/IO0gr. Nilai unsur $\mathrm{N}$ tertinggi terdapat pada area kajian B, yaitu sebesar $709,66 \mathrm{mg} / \mathrm{kg}$. Nilai unsur $\mathrm{P}$ tertinggi terdapat pada area kajian A, yaitu sebesar $544,77 \mathrm{mg} / \mathrm{kg}$. Nilai unsur $\mathrm{K}$ tertinggi terdapat pada area kajian $\mathrm{C}$, yaitu sebesar
I566,78 mg/kg. Nilai KPK tanah tertinggi terdapat pada area kajian B dan C sebesar I0,93 me/IO0gr.

Nilai densitas atau kerapatan relatif (KR), pada area kajian A jenis strata semak dengan nilai $\mathrm{KR}$ teritinggi terletak pada stand I2, yaitu Bambusa sp. sebesar 50\%. Area kajian B nilai KR tertinggi terletak pada stand 32, yaitu jenis Bambusa sp. sebesar 96,43\%. Area kajian C nilai KR tertinggi terletak pada stand 50, yaitu Bambusa sp. sebesar 80,95\%. Perbedaan nilai KR jenis di tiap area kajian ini disebabkan oleh adanya perbedaan kemampuan reproduksi, penyebaran, dan daya adaptasi terhadap lingkungan. Menurut Astuti (2009: 59), menyatakan bahwa nilai KR tinggi dipengaruhi oleh faktor lingkungan yang sesuai dengan pertumbuhan dan perkembangan jenis tumbuhan tersebut.

Nilai frekuensi relatif (FR) tertinggi pada area kajian A terletak pada stand I2, yaitu Bambusa sp. sebesar 44,44\%. Pada area kajian B nilai FR tertinggi terletak pada stand 32, yaitu Bambusa sp. sebesar 88,89\%. Pada area kajian C nilai FR tertinggi terletak pada stand 50, yaitu Bambusa sp. sebesar 70\%. Berdasarkan frekuensi kehadiran jenis tersebut telah menggambarkan penyebaran jenis strata semak di area tersebut. Apabila frekuensi kehadirannya tinggi berarti jenis itu sering ditemukan pada area kajian itu. Di dalam ekologi, frekuensi digunakan untuk menyatakan proporsi antara jumlah sampel yang berisi suatu jenis tertentu terhadap jumlah sampelnya. Jika jumlah makin banyak stand yang di dalamnya ditemukan suatu jenis, maka semakin besar frekuensi jenis tersebut (Indriyanto, 2006: I43). Berkaitan dengan nilai frekuensi suatu jenis, menurut Greig-Smith (Arrijani, dkk., 2006: I48), menyatakan bahwa nilai frekuensi suatu jenis dipengaruhi oleh densitas dan pola distribusinya. Nilai distribusi hanya dapat memberikan informasi tentang kehadiran tumbuhan tertentu dalam suatu stand dan belum dapat memberikan gambaran tentang jumlah individu pada masing-masing stand. Jenis-jenis yang memiliki nilai densitas dan frekuensi tertinggi termasuk dalam kategori jenis yang memiliki kemampuan adaptasi yang baik terhadap kondisi lingkungan.

Nilai dominansi relatif (DR) tertinggi pada area kajian A terletak pada stand I2, yaitu Bambusa sp. sebesar $88,53 \%$. Pada area kajian B nilai DR tertinggi terletak pada stand 32, yaitu Bambusa sp. sebesar 99,95\%. Pada area kajian C nilai DR tertinggi terletak pada stand 5I, yaitu Bambusa sp. sebesar 99,83\%. Tingginya nilai dominansi ditentukan oleh kerapatan jenis dan ukuran rata-rata diameter batang. Nilai kerapatan jenis Bambusa sp. di stand 12 sebesar 50\%. Nilai kerapatan jenis Bambusa sp. di stand 32 sebesar $96,43 \%$, dan di stand 5 I sebesar $64,52 \%$

Indeks nilai penting tertinggi yang pertama, yaitu Bambusa sp. dengan nilai 120,77\%. Menurut Heyne (Nadeak, 2009: 4) menyatakan bahwa bambu merupakan tanaman yang berbentuk perdu. dengan 
batang tegak, memanjat dan bercabang-cabang serta dapat mencapai umur panjang yakni 40-60 tahun. Tanaman bambu memiliki akar rimpang yang sangat kuat. Struktur akar ini menjadikan bambu dapat mengikat tanah dan air dengan baik. Sehingga tanaman bambu ini mampu memperbaiki lahan kritis, dapat menjernihkan air sungai, mengatasi erosi dan tanah longsor (Hingmadi, 2013). Bambu dapat tumbuh di berbagai jenis tanah dengan tingkat keasaman $(\mathrm{pH})$ tanahnya 5,6 sampai 6,5 , suhu udara $27^{\circ} \mathrm{C}-36^{\circ} \mathrm{C}$, kelembaban udara $\pm 80 \%$ (Anonim, $201 \mathrm{I}$ ).

Hasil indeks diversitas yang tertinggi pada area kajian A terletak pada stand I dengan nilai H' 0,74, area kajian B terletak pada stand 37 dengan nilai $\mathrm{H}^{\prime} 0,69$, dan area kajian $\mathrm{C}$ terletak pada stand 48 dengan nilai H' 0,76. Pada stand I, kondisi lingkungan abiotik yang terukur, yaitu kelembaban udara $75 \%$, suhu udara $26,5^{\circ} \mathrm{C}$, suhu tanah $28^{\circ} \mathrm{C}$, dan $\mathrm{pH}$ tanah 5,5

Hasil penghitungan analisis cluster faktor-faktor lingkungan abiotik terhadap pengelompokkan stand vegetasi strata semak menunjukkan bahwa faktor lingkungan abiotik, yaitu kelembaban udara, suhu tanah, dan $\mathrm{pH}$ tanah tidak berkaitan dengan pola pengelompokkan stand vegetasi strata semak karena hasil signifikansinya $>0,05$. Tetapi suhu udara, unsur $\mathrm{N}$, unsur $\mathrm{P}$, unsur $\mathrm{K}$, dan KPK tanah berkaitan dengan pola pengelompokkan stand vegetasi strata semak karena hasil signifikansinya $<0,05$.

Hasil penelitian agar dapat dimanfaatkan secara efektif dan efisien, perlu diseleksi. Penyeleksian ini mengacu pada syarat-syarat sumber belajar. Syarat-syarat sumber belajar yang dimaksud oleh Djohar (Suratsih, 2010:10), diantaranya kejelasan potensi, kesesuaian dengan kejelasan potensi, kesesuaian dengan tujuan pembelajaran, kejelasan sarana, kejelasan informasi yang diungkap, kejelasan pedoman eksplorasi, kejelasan perolehan yang diharapkan.

\section{Simpulan}

Jenis-jenis strata semak yang ditemukan di sempadan Sungai Tepus Sleman Yogyakarta ada 19 jenis. Jenis strata semak yang memiliki peranan paling besar berdasarkan rerata INP tertinggi di sempadan Sungai Tepus Sleman, Yogyakarta yaitu Bambusa sp. 120,77\%, Musa paradisiaca L. 67,92\%, dan Manihot utillissima Pohl. 30,07\%.

Rerata indeks diversitas di sempadan Sungai Tepus Sleman, Yogyakarta menunjukkan nilai 0,54. Nilai ini menunjukkan bahwa vegetasi strata semak di sempadan Sungai Tepus termasuk dalam kategori rendah. Artinya bahwa stabilitas ekosistem di daerah tersebut kurang baik.

Berdasarkan uji analisis cluster pola pengelompokkan stand dibagi menjadi 2 cluster, yaitu cluster I dan cluster 2. Faktor lingkungan abiotik yang berkaitan dengan pola pengelompokkan stand vegetasi strata semak adalah suhu udara, unsur $\mathrm{N}$, unsur $\mathrm{P}$, unsur
K, dan KPK tanah. Akan tetapi, faktor lingkungan abiotik yang tidak berkaitan dengan pengelompokkan stand, yaitu kelembaban udara, suhu tanah dan $\mathrm{pH}$ tanah.

\section{Daftar Pustaka}

Anonim. 2011.”Potensi Bambu sebagai Tanaman Konservasi Daerah Aliran

Sungai”. Http://balittri.litbang.deptan.go.id/index.php/i novasi-teknologi/4 -artikel/77-potensi-bambu-sebagaitanaman-konservasi-daerah-aliran-sungai. Diunduh pada tanggal 2I Agustus 2013, jam I3:17 WIB.

Arrijani, 6. "Analisis Vegetasi Hulu DAS Cianjur Taman Nasional Gunung Gede-Pangrango". Jurnal Biodiversitas. Volume 7. Nomor 2. $\underline{\mathrm{dkk}}$. 200

Astuti, Seneng Sri. 2009. Struktur dan Komposisi Vegetasi Pohon dan Pole di Sekitar Jalur Wisata Taman Wisata Alam Sicikeh-Cikeh Kabupaten Dairi Sumatera Utara. Medan: FMIPA Universitas Sumatera Utara.

Djufri. 2003. “Analisis Vegetasi Spermatophyta di Taman Hutan Raya (Tahura) Seulawah Aceh Besar. Banda Aceh: Universitas Syiah Kuala”. Jurnal Biodiversitas. Volume 4. Nomor I.

Fitriyani, Ana, Ragil Septiningsih, dan Sofyan Asifudin. 2013. Endemik dan Kosmopolit.

Http://kyonktara.blogspot.com/2013/04/makalahendemik-dan-kosmopolit.html. Diunduh pada tanggal 05 September 2013, jam I4:47 WIB.

Heddy, Suwarsono. 2012. Metode Analisis Vegetasi dan Komunitas. Jakarta: Rajawali Press.

Hendriani, Yeni. 2005. Memanfaatkan Lingkungan sebagai Sumber Belajar. Bandung: Pusat Pengembangan dan Pemberdayaan Pendidik dan Tenaga Kependidikan IPA.

Hingmadi, Deny. 20II. "Pelestarian Hutan Bambu untuk Mengatasi Pemanasan Global”. Http://kebunbambu.blogspot.com/2013/01/pelestarian-hutanbambu-untuk-mengatasi.html. Diunduh tanggal 2 I Agustus 2013, jam I3.10 WIB.

Indriyanto. 20I0. Ekologi Hutan. Jakarta: Bumi Aksara. Nadeak, Mery Natalia. 2009. Deskripsi Budidaya dan Pemanfaatan Bambu di Kelurahan Balumbung Jaya (Kecamatan Bogor Barat) dan Desa Rumpin (Kecamatan Rumpin), Kabupaten Bogor, Jawa Barat. Bogor: IPB.

Soegianto, Agus. 1994. Ekologi Kuantitatif: Metode Analisis Populasi dan Komunitas. Surabaya: Usaha Nasional.

Suratsih. 2010. Pengembangan Modul Pembelajaran Biologi Berbasis Potensi Lokal dalam Kerangka Implementasi KTSP SMA di Yogyakarta. Yogyakarta: UNY. 